\title{
Diagnostic accuracy of small breast epithelial mucin mRNA as a marker for bone marrow micrometastasis in breast cancer: a pilot study
}

\author{
Manuel Valladares-Ayerbes ${ }^{1,2}$, Pilar Iglesias-Díaz ${ }^{3}$, Silvia Díaz-Prado ${ }^{2,4}$, Daniel \\ Ayude $^{2,5}$, Vanessa Medina ${ }^{2}$, Mar Haz $^{2}$, Margarita Reboredo ${ }^{1}$, Silvia Antolín ${ }^{1}$, \\ Lourdes Calvo ${ }^{1}$, Luis M. Antón-Aparicio ${ }^{1,4}$
}

1. Medical Oncology Department, La Coruña University Hospital, La Coruña, Spain

2. Oncology Research Program, Biomedical Research Institute (INIBIC), La Coruña, Spain

3. Pathology Department, La Coruña University Hospital, La Coruña, Spain

4. Medicine Department, La Coruña University, La Coruña, Spain

5. Pontevedra, Spain

\begin{abstract}
Background. Detection of isolated tumour cells (ITC) in the blood or minimal deposits in distant organs such as bone marrow (BM) could be important to identify breast cancer patients at high risk of relapse or disease progression. PCR amplification of tissue or tumour selective mRNA is the most powerful analytical tool for detection of this micrometastasis. We have evaluated for the first time, the diagnostic accuracy of small breast epithelial mucin (SBEM) as a potential marker for BM micrometastasis in breast cancer.

Methods. A nested RT-PCR assay for detection of SBEM mRNA was compared with immunocytochemistry (ICC) with anticytokeratin $A E 1 / A E 3$ antibody in paired samples obtained from the BM of breast cancer patients. Associations of $S B E M$ mRNA detection in BM and clinical and pathological parameters were evaluated. $S B E M$ mRNA status and time to breast cancer progression were analysed using Kaplan-Meyer curves.

Results. Fifty stages I-IV breast cancer female patients were prospectively included in our study. SBEM specific transcript was found in BM in $26 \%$ of the patients. Detection rate was similar to the percentage of patients with ITCs detected using ICC (24\%). SBEM mRNA in BM aspirates were significantly associated with presence of clinically active disease, including locally advanced and metastatic patients (47\%, $P=0.021)$ and tumours with positive hormonal receptors $(36.7 \%, P=0.035)$. In addition association with Her $2 /$ neu over-expression $(44.4 \%, P=0.051)$ and low proliferating tumours $(36 \%, P=0.067)$ were close to significant levels. When we analysed time to breast cancer progression adjusting for grade or hormone receptor status, presence of $S B E M$ mRNA in BM defines distinct prognostic groups.

Conclusions. SBEM might represent a suitable marker for molecular detection of ITCs in BM in breast cancer patients. Analysis of prognostic value for SBEM mRNA-based assay should take into account the heterogeneity and different molecular subtypes of breast cancer.
\end{abstract}

\section{Keywords}

Isolated tumour cells; Small breast epithelial mucin Breast tumour cells Minimal disease RNA-based methods

\section{Abbreviations}

ITC, Isolated tumour cells; ICC, Immunocytochemistry; CK, Cytokeratin; RT-PCR, Reverse-transcriptase polymerase-chain reaction; SBEM, Small breast epithelial mucin; BM, Bone marrow; TTP, Time to breast cancer progression; HR, Hormonal receptors 


\section{Introduction}

Breast cancer is the most common type of cancer in European women, accounting for 429,900 cases in 2006 (Ferlay et al. 2007). Relative survival from breast cancer in women has improved steadily in all European countries in recent years. However age-standardized 5-year relative survival remains within a range of 78.1-80\% (Verdecchia et al. 2007). Metastatic haematogenous spreading is one of the most important factors affecting the prognosis of carcinoma patients, including breast cancer. Circulating tumour cells and occult metastasis (micrometastasis) are considered early events in the progression of breast cancer. Detection of carcinoma cells in the blood or minimal deposits in distant organs such as bone marrow (BM) could be important to identify patients at high risk of relapse or disease progression (Pantel and Alix-Panabieres 2007). A pooled analysis of data from different clinical studies found strong evidence that the presence of isolated tumour cells (ITC) in BM by means of immunocytochemical-based detection is associated with a poor prognosis in stage I-III breast cancer patients (Braun et al. 2005).

As stated previously, immunocytochemistry (ICC) with anticytokeratin (CK) antibodies would be considered as a benchmark technique for ITC detection. Thus, studies evaluating molecular methods of ITC detection and novel markers would be performed in comparison with standardized ICC (Braun and Naume 2005). PCR amplification of tissue or tumour selective mRNA is the most powerful analytical tool for detection of this circulating or micrometastatic cells. Cytokeratins and mammaglobin are among the most frequent mRNA markers used in different reverse transcriptasepolymerase chain reaction (RT-PCR) assays in breast cancer patients. However down-regulation of mRNA marker in tumour cells (Woelfle et al. 2003) or low-level transcription of selected targets in the haematopoietic compartment (Kruger et al. 2001) could compromise both sensitivity and specificity of molecular methods.

The selection of novel breast-specific transcripts and the development of multi-marker RTPCR assays are clearly outstanding research questions. In this context we have evaluated the diagnostic accuracy of small breast epithelial mucin (SBEM) as a potential marker for BM micrometastasis in breast cancer. The SBEM gene (GenBank No. AF414087] was identified by Miksicek et al. (2002) using the cDNA xProfiler tool. SBEM product is similar to proteins $B 511 \mathrm{~s}$ (Houghton et al. 2001) and BS106 (Colpitts et al. 2002). The SBEM gene is predicted to code for a low molecular weight glycoprotein with highly similarity to sialomucins, including $M U C 1$. Thus the SBEM gene is also known as Mucin-like 1 gene (GeneID: 118430). However SBEM gene has shown more specific patterns of expression, limited to breast and salivary glands.

Using an in silico approach (Ayerbes et al. 2008) we have analysed the expression of SBEM tags in a series of human breast carcinomas SAGE libraries. In addition we developed a model system based on RT-PCR for SBEM mRNA to detect isolated breast tumour cells. Using SBEM nested approach we could detect up to one cancer cell among $1 \mu \mathrm{g}$ of normal BM RNA, similar to the results obtained with mammaglobin $(h M A M)$ mRNA amplification. No significant expression for $S B E M$ was found in haematopoietic cell-lines neither in 23 controls BM analysed.

The aim of our study was to compare directly the detection rate of ITC in BM by SBEM RTPCR and ICC. Molecular assay for detection of SBEM mRNA in BM of breast cancer patients was compared with a benchmark technique of disseminated tumour cell detection as ICC with anticytokeratin $A E 1 / A E 3$ antibody. Exploratory analysis included associations of SBEM mRNA detection in BM and clinical and pathological parameters. In addition SBEM mRNA status in BM in relation with time to breast cancer progression were analysed. 


\section{Methods}

Patients

Consecutive female breast cancer outpatients were included from the medical oncology unit at University hospital in La Coruña, Spain. Inclusion criteria were: Confirmed pathologic diagnosis of invasive breast cancer; stage I-III with no prior systemic therapy for breast cancer; stage IV patients with no previous systemic therapy or in confirmed progression after such treatment; written informed consent. Exclusion criteria were defined as: previous invasive epithelial cancer; coagulopathies or thrombopenia $(<20,000)$; any previous systemic therapy for breast cancer except stage IV patients with confirmed progressive disease; prior pelvic radiation; previous diphosphonate therapy.

The diagnostic work-up included clinical examination, blood sampling with CA 15.3 and CEA serum determination, mammography, chest $\mathrm{x}$-ray, abdominal ultrasound and bone scan. Computed tomography scanning of the chest, abdomen and pelvis was performed on stage IV patients.

After informed, written consent, BM aspiration was performed under local anaesthesia, just before systemic treatment for pathological confirmed breast cancer. In patients who first underwent surgery as loco-regional treatment for primary disease, BM aspirate was obtained at least 2-3 weeks after operation but before 8 weeks. Otherwise BM samples were obtained before neo-adjuvant chemotherapy or in presence of active metastatic disease. BM was aspirated from anterior or posterior iliac crest unilaterally. Skin incision was made to avoid contamination with epidermal cells.

The study was approved by the Institutional Review Board of the Ethic Committee of Clinical Investigation of Galicia (Spain) and written informed consent was obtained from all patients.

\section{Analysis of primary tumour and axillary lymph nodes}

The primary tumour and axillaries lymph nodes collected during surgery were processed on a routine diagnostic basis. Histological tumour type, tumour size and nodal involvement were analysed, and the disease was staged according to the TNM system (American Joint Committee on Cancer, AJCC. $5^{\mathrm{a}}$ edition). Tumour grading was performed according to modified BloomRichardson score. Tumour tissue immunostainings were performed using mouse monoclonal antibodies $(\mathrm{mAb})$ against oestrogen receptor $(\mathrm{ER})$ and progesterone receptor $(\mathrm{PgR})$; clones ER6F11/2 and PGR-312, respectively; Novocastra, Ki-67 antigen (MIB-1, DAKO) and rabbit polyclonal antibody against Her2/neu (DAKO). Immunopositivity was recorded if $\geq 10 \%$ (ER, $\mathrm{PgR}$ ) of the nucleus of tumour cells were immunostained. In addition, Her $2 /$ neu required distinct membranous staining for being considered positive.

\section{Preparation of the bone marrow}

Unilateral BM aspiration was performed from anterior or posterior iliac crests under local anaesthesia and transferred into heparinized tubes. One aliquot of one-third and at least $1 \mathrm{ml}$ was used for mRNA isolation. Two-thirds were subjected to mononuclear cell (MNC) separation by density centrifugation using Lymphoprep (Nycomed, Oslo, Norway). MNCs were collected from the interphase layer and washed twice in PBS (Life Technologies, Inc.) with 10\% FCS. Cytospins were prepared $\left(5 \times 10^{5} \mathrm{MNCs} /\right.$ slide $)$ on polylysine-coated slides in a Hettich cytocentrifuge. The cytospins were air-dried at RT overnight before freezing at $-80^{\circ} \mathrm{C}$ or immunostaining.

Bone marrow aliquots destined to mRNA extraction were stabilized immediately after aspiration with the guanidinium lysis buffer RNA/DNA Stabilization Reagent for Blood/BM (Roche) at $10 \%$ (vol/vol). Immediate stabilization of the sample using a commercial reagent effectively protects mRNA, avoids loss of target mRNA and ensures higher reproducibility in 
clinical samples. Furthermore, sedimentation of all tumour cells in the mononuclear fraction (as needed for ICC analysis) is not warranted by density centrifugation (Choesmel et al. 2004).

Bone marrow lysates were stored at $-80^{\circ} \mathrm{C}$ until mRNA isolation. The mRNA isolation procedure was performed using mRNA Isolation Kit for Blood/BM (Roche) following manufacturer's instructions. Briefly, total nucleic acid fraction was adsorbed to magnetic glass particles and poly (A) + RNA was captured by using biotin-labelled oligo(dT) and streptavidincoated magnetic particles. Elution was performed on each mRNA preparation in $12 \mu \mathrm{l}$ RNase-free redistilled water. Purified poly $(\mathrm{A})+\mathrm{RNA}$ was further processed in RT-PCR or stored at $-80^{\circ} \mathrm{C}$ until use.

\section{Immunocytochemical staining}

Immunocytochemical staining was performed using the Vectastain ABC-AP kit (VECTOR) following manufacturer's procedure. Slides $\left(5 \times 10^{5} \mathrm{BM} \mathrm{MNCs}\right)$ were incubated with the anticytokeratin mAbs AE1/AE3 (DAKO). At least two slides were incubated with a negative control antibody of the same immunoglobulin isotype ( $\operatorname{IgG} 1)$. The visualization stage included Vector Red alkaline phosphatase substrate kit. Endogenous alkaline phosphatase activity was inhibited by addition of levamisole. The slides were counterstained with Gills's haematoxylin to visualize nuclear morphology. The slides were manually screened by light microscopy by one of the pathologists (PID) with no knowledge about clinical data or RT-PCR status. All of the stained cells were closely evaluated. Categorization of CK immunopositive cells was performed according to the recommended guidelines (Borgen et al. 1999). Presence of micrometastasis was recorded as positive when stained cells shown typical tumour cell morphology or when these immunostained cells lacked haematopoietic characteristics and were not found in negative controls.

\section{RNA isolation and RT-PCR}

The mRNA isolation procedure was performed using mRNA Isolation Kit for Blood/BM (Roche) following manufacturer's instructions. Briefly, total nucleic acid fraction was adsorbed to magnetic glass particles and poly $(\mathrm{A})+\mathrm{RNA}$ was captured by using biotin-labelled oligo(dT) and streptavidin-coated magnetic particles. Elution was performed on each mRNA preparation in $12 \mu \mathrm{l}$ RNase-free redistilled water. Purified poly (A) + RNA was further processed in RT-PCR or stored at $-80^{\circ} \mathrm{C}$ until use.

The reverse transcription was performed using the SuperScript II First-Strand Synthesis System for RT-PCR (Invitrogen) using random hexamers according to manufacturer's instructions. PCR amplifications were carried out with AmpliTaq Gold PCR Master Mix (Applied Biosystems). First round PCR amplification of SBEM mRNA was performed using specific primers (SBEM-U-O and SBEM-L-O described by Miksicek et al. (2002). In the nested-PCR new primer pairs (SBEM-S-I 5'TGA TCT TCA GGT CAC CAC CA3' and SBEM-A-I 5'TGG ATA CGT GTC AGC TGG AG3') were used, designed using software available on the Internet (Rozen and Skaletsky 2000). The gene and mRNA structure of SBEM and primers are shown in Fig. 1, according to AceView. 


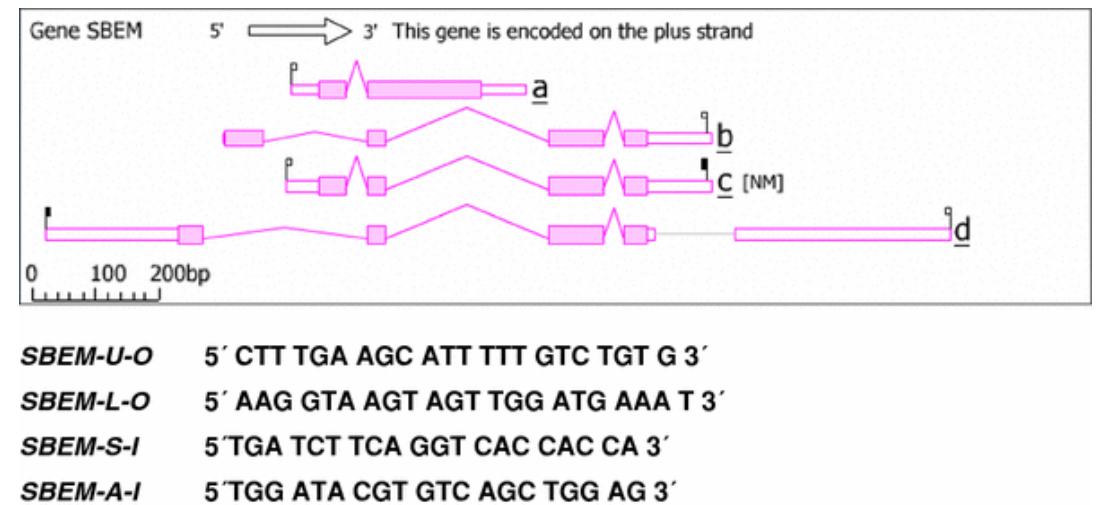

Fig. 1. Small breast epithelial mucin gene diagram and primers. The SBEM gene maps on chromosome 12, at $12 \mathrm{q} 13$. It contains five introns and four exons. Transcription produces four (a-d) alternatively spliced mRNAs. Designed primers for RT-PCR are shown

First round PCR was performed in $50 \mu \mathrm{l}$ of reaction mixture containing $2 \mu \mathrm{l}$ of template cDNA, deionized water, outer SBEM primers $\mathrm{U}$ and $\mathrm{L}, 1 \mu \mathrm{l} 20 \mu \mathrm{M}$ of each, and PCR Master Mix (2X) $25 \mu \mathrm{l}$. In $S B E M$ nested reaction $1 \mu \mathrm{l}$ of first round PCR template and $0.5 \mu \mathrm{l}$ at $20 \mu \mathrm{M}$ of each inner $S B E M$ primer pair were used. For first round SBEM PCR amplification, an initial activation at $95^{\circ} \mathrm{C}$ was used for $5 \mathrm{~min}$, followed by 35 cycles of $95^{\circ} \mathrm{C}(30 \mathrm{~s}), 54^{\circ} \mathrm{C}(1 \mathrm{~min})$ and $72^{\circ} \mathrm{C}(1 \mathrm{~min})$. Finally, the last extension was at $72^{\circ} \mathrm{C}$ for $7 \mathrm{~min}$. For $S B E M$ nested reaction, an initial activation at $95^{\circ} \mathrm{C}$ for 2 min was used, followed by 20 cycles of $95^{\circ} \mathrm{C} 40 \mathrm{~s}, 62^{\circ} \mathrm{C} 15 \mathrm{~s}$ and $72^{\circ} \mathrm{C} 20 \mathrm{~s}$. Last extension was at $72^{\circ} \mathrm{C}$ for $7 \mathrm{~min}$. PCR products were electrophoresed through agarose gel and stained with $5 \%$ ethidium bromide. Beta-2 microglobulin serves as a positive control target. Negative controls were included in each experiment.

\section{DNA sequencing}

Polymerase chain reaction products were used as template DNA. Products were purified by enzymatic method (ExoSAP-It, Amersham USB). DNA sequencing was performed in a reference facility on ABI 3700 (Applied Biosystems) using Big Dye Terminators. Sense SBEM-specific primers were used.

\section{Study design and statistical analysis}

The study was designed as prospective and observational. Its primary objective was to estimate and compare the proportion of breast cancer patients with a positive mRNA transcript in BM with respect to the proportion of patients with $\mathrm{CK}$-positive tumour cells in $\mathrm{BM}$ as a reference standard. Both early stage and metastatic patients were included in the study in order to estimate these proportions in a cohort of patients commonly found in every-day clinical practice. Detection rate using anti-CK antibodies is related to different variables including clinical and methodological parameters (Pantel et al. 1994). To obtain a power of $80 \%$ and $P=0.05$ to find out differences using McNemar's test with the continuity correction, sample size was calculated in 47 pairs, considering that $\mathrm{CK}$ positive cells are detected in $\mathrm{BM}$ in $25 \%$ of the patients, mRNA marker expression could be detected in $45 \%$ and an estimated $25 \%$ of discordant pairs.

Exploratory analysis included associations of SBEM mRNA detection in BM and clinical and pathological parameters. The relationship between categorical variables was analysed by Chisquared test with continuity correction when applicable, or Fisher's exact test. SBEM mRNA status in BM and time to breast cancer progression (TTP), defined as the period between BM aspirate and first recurrence, were analysed using Kaplan-Meyer curves and compared with the 
log-rank test. The joint effect of covariables was examined using the Cox proportional hazard regression model. $P$ values $<0.05$ were considered statistically significant. Statistical analysis was performed by SPSS (Version 14.0)

\section{Results}

\section{Patients and clinical data}

From February 2002 to May 2003, 50 breast cancer female patients were included. Clinical characteristics are shown in Table 1. BM aspiration was performed after R0 surgery in 33 patients. In 17 patients BM samples were obtained before neo-adjuvant chemotherapy for locally advance disease or in presence of active metastatic disease. Thus, this subgroup of patients was prospectively defined to have clinically active disease at the time of BM sampling. The median follow-up time was 258.5 weeks (range 18-298 weeks). Breast cancer progression was detected in 15 patients $(30 \%)$. There were six relapses from stage I to III patients and nine progressions of metastatic disease. Progression occurred at median time of 61 weeks (range 13-248 weeks). Seven patients died of metastatic disease. 
Table 1. Clinical characteristics of the patients

\begin{tabular}{|c|c|c|}
\hline & $n$ & $\%$ \\
\hline Age (years) & $53.6( \pm 12.18)$ & $32-87$ \\
\hline$<50$ years & 23 & 46 \\
\hline$\geq 50$ years & 27 & 54 \\
\hline \multicolumn{3}{|l|}{ Stage } \\
\hline I & 13 & 26 \\
\hline II & 19 & 38 \\
\hline III & 7 & 14 \\
\hline IV & 11 & 22 \\
\hline \multicolumn{3}{|l|}{ pT } \\
\hline pT1 & 18 & 36 \\
\hline pT2 & 19 & 38 \\
\hline pT3 & 9 & 18 \\
\hline pT4 & 4 & 8 \\
\hline \multicolumn{3}{|l|}{$\mathrm{pN}$} \\
\hline pNO & 21 & 42 \\
\hline $\mathrm{pN} 1$ & 25 & 50 \\
\hline $\mathrm{pN} 2$ & 3 & 6 \\
\hline $\mathrm{pN} 3$ & 1 & 2 \\
\hline \multicolumn{3}{|l|}{ Hormonal receptors } \\
\hline Negative & 20 & 40 \\
\hline Positive & 30 & 60 \\
\hline \multicolumn{3}{|l|}{ Histology } \\
\hline Ductal & 35 & 70 \\
\hline Lobular & 4 & 8 \\
\hline Other & 11 & 22 \\
\hline \multicolumn{3}{|l|}{ Her2 } \\
\hline Unknown & 4 & 8 \\
\hline $0-1$ & 25 & 50 \\
\hline 2 & 4 & 8 \\
\hline 3 & 17 & 34 \\
\hline HR and Her2 negative & 12 & 24 \\
\hline \multicolumn{3}{|l|}{ Vascular invasion } \\
\hline Unknown & 8 & 16 \\
\hline No & 23 & 46 \\
\hline Yes & 19 & 38 \\
\hline \multicolumn{3}{|l|}{ Histological grade } \\
\hline Unknown & 5 & 10 \\
\hline 1 & 10 & 20 \\
\hline 2 & 17 & 34 \\
\hline 3 & 18 & 36 \\
\hline \multicolumn{3}{|l|}{ Ki-67 } \\
\hline Unknown & 2 & 4 \\
\hline$<20 \%$ & 25 & 50 \\
\hline$\geq 20 \%$ & 23 & 46 \\
\hline
\end{tabular}


First round PCR amplification for SBEM mRNA in BM shows positive results in four patients (8\%). Nested amplifications were positive in another nine patients (18\%). Thus, globally, RT-PCR for $S B E M$ was positive in BM in 13 out 50 breast cancer patients (26\%; standard error 0.06$)$.

\section{Cytokeratin immunocytochemistry}

Isolated tumour cells in BM were detected using anti-cytokeratin mAbs AE1/AE3 and standardized morphological criteria. At least $2 \times 10^{6} \mathrm{BM}$ MNC cells were screened per patient. BM aspirate did not obtain enough samples for immunocytochemical analysis in one patient with bone metastasis. Presence of ITC in BM was found in 12 patients (24\%; standard error 0.06). The number of tumour cells detected were: one (four patients), two (two patients), three (three patients), six (one patient) and ten or more in two patient.

\section{Diagnostic accuracy of SBEM RT-PCR}

The primary objective of our study was to estimate and compare the proportion of breast cancer patients with a positive $S B E M$ mRNA transcript in BM in relation to the proportion of patients with CK-positive tumour cells in BM as a standard reference. Results are shown in Table 2. RT-PCR for SBEM was positive in $26 \%$ of the patients. Presence of ITC using CK staining was found in $24 \%$ of the patients. According to McNemar's test, there was no difference in ITC detection in BM between SBEM RT-PCR and ICC [two-tailed $P$ value $=1$ (odds ratio $1.125 ; 95 \%$ confidence interval $0.385-3.351)]$. The kappa value was low $(0.094, P=0.56)$.

Table 2. Comparison between SBEM RT-PCR and cytokeratin immunocytochemistry for the detection of disseminated epithelial cells in bone marrow from breast cancer patients

\begin{tabular}{lllll}
\hline & & \multicolumn{2}{l}{ Cytokeratin immunocytochemistry } & $P^{\mathrm{a}}$ \\
\cline { 3 - 4 } & & + & - & NS \\
\hline SBEM mRNA in bone marrow & + & 4 & 9 & \\
& - & 8 & 29 \\
\hline
\end{tabular}

${ }^{\mathrm{a}} \mathrm{McNemar}$ 's test

A concordance of $66 \%$ (33 of 50; 95\% CI 51.14-78.41) was found between SBEM RT-PCR and ICC. Sensitivity and specificity of SBEM RT-PCR, considering ICC as a reference, were $33.3 \%$ (95\% CI 11.3-64.6) and 76.32\% (95\% CI 59.38-87.97) respectively.

Breast cancer progression was found in six patients (40\%) with SBEM mRNA in BM but only in two patients $(13.3 \%$ ) with CK positive cells in BM. Diagnostic accuracy for SBEM RT-PCR for breast cancer progression was estimated in $68 \%$ (95\% CI 53.2-80\%). By contrast, accuracy for CK-ICC was only 54\% (95\% CI 39.5-67.9\%). 
Associations of BM status and clinical and pathologic characteristics of the patients are shown in Table 3. SBEM mRNA in BM aspirates were significantly associated with presence of clinically active disease $(47 \%, P=0.021)$ and tumours with positive hormonal (oestrogen and/or progesterone) receptors $(36.7 \%, P=0.035)$. Interestingly, association with Her2/neu overexpression $(44.4 \%, P=0.051)$ and low proliferating tumours, defined as nuclear Ki67 staining $<20 \%(36 \%, P=0.067)$ were nearly significant. 
Table 3. Associations of bone marrow status and clinicopathologic characteristics of the patients

\begin{tabular}{|c|c|c|c|c|c|c|}
\hline \multirow{2}{*}{ Characteristic } & \multicolumn{3}{|c|}{ SBEM RT-PCR positive } & \multicolumn{3}{|c|}{ CK-ICC positive } \\
\hline & Number & $\%$ & Significance & Number & $\%$ & Significance \\
\hline Age & & & 0.526 & & & 0.730 \\
\hline$<50$ years & 5 & 10 & & 5 & 10 & \\
\hline$\geq 50$ years & 8 & 16 & & 7 & 14 & \\
\hline Stage & & & 0.180 & & & 0.825 \\
\hline $\mathrm{I}-\mathrm{II}$ & 6 & 18.7 & & 8 & 25 & \\
\hline III-IV & 7 & 38.9 & & 4 & 22.2 & \\
\hline Active disease & & & $0.021^{\mathrm{a}}$ & & & 0.728 \\
\hline Yes & 8 & 47 & & 5 & 29.4 & \\
\hline No & 5 & 15.2 & & 7 & 21.2 & \\
\hline Tumour status & & & 0.149 & & & 0.791 \\
\hline $\mathrm{T} 1-2$ & 7 & 19.4 & & 9 & 25 & \\
\hline T3-4 & 6 & 42.8 & & 3 & 21.4 & \\
\hline Lymph node status & & & 0.340 & & & 0.979 \\
\hline No & 4 & 19.0 & & 5 & 23.8 & \\
\hline $\mathrm{N}+$ & 9 & 31.0 & & 7 & 24.1 & \\
\hline Metastasis & & & 0.126 & & & 0.609 \\
\hline M0 & 8 & 20.5 & & 10 & 25.6 & \\
\hline M1 & 5 & 45.5 & & 2 & 18.2 & \\
\hline Histological grade & & & 0.891 & & & $0.008^{\mathrm{a}}$ \\
\hline $1-2$ & 7 & 25.9 & & 2 & 7.4 & \\
\hline 3 & 5 & 27.8 & & 8 & 44.4 & \\
\hline Unknown & 1 & 20 & & 2 & 40 & \\
\hline Hormonal receptors & & & $0.035^{\mathrm{b}}$ & & & 0.506 \\
\hline Positive & 11 & 36.7 & & 6 & 30 & \\
\hline Negative & 2 & 10 & & 6 & 20 & \\
\hline Her2/neu & & & $0.051^{\mathrm{b}}$ & & & 0.829 \\
\hline Positive & 8 & 44.4 & & 4 & 22 & \\
\hline Negative & 5 & 17.9 & & 7 & 25 & \\
\hline Unknown & 0 & & & 1 & 25 & \\
\hline Vascular invasion & & & 0.156 & & & 0.155 \\
\hline Positive & 7 & 36.9 & & 3 & 15.8 & \\
\hline Negative & 3 & 13.0 & & 5 & 21.7 & \\
\hline Unknown & 3 & 37.5 & & 4 & 50 & \\
\hline $\mathrm{Ki}-67$ staining & & & $0.067^{\mathrm{b}}$ & & & 0.616 \\
\hline$<20 \%$ & 9 & 36.0 & & 5 & 20 & \\
\hline$\geq 20 \%$ & 3 & 13 & & 6 & 26.1 & \\
\hline Unknown & 1 & 50 & & 1 & 50 & \\
\hline CA 15.3 & & & 0.719 & & & 0.928 \\
\hline$\leq 35$ & 9 & 24.3 & & 9 & 24.3 & \\
\hline$>35$ & 4 & 30.8 & & 3 & 23.1 & \\
\hline
\end{tabular}

${ }^{a} P$ value computed by Fisher's exact test

${ }^{\mathrm{b}} P$ value computed by Pearson's Chi-square test 
Although positive results for SBEM mRNA were more frequent in patients with stage III-IV (38.9\%), T3-T4 tumours (42.8\%), positive axillaries lymph nodes $(31 \%)$, presence of metastasis $(45.5 \%)$ and vascular invasion $(36.9 \%)$ these associations did not reach statistically significance.

Presence of CK-positive tumour cells in BM was associated only with histological grade 3 $(P=0.008)$.

Kaplan-Meier survival analysis (Fig. 2) suggest a reduced time to breast cancer progression (TTP) among the SBEM mRNA BM positive patients, although this was not significant (log-rank test, $P=0.150$ ). Subgroup analysis was performed (Table 4). Interestingly, when TTP was analysed in relation to the grade of the tumours concomitantly with the presence or absence of SBEM mRNA in BM, a statistically significant association was observed (long-rank test, $P=0.045)$. In addition and in spite of limited number of patients, presence of $S B E M$ in BM defines a very poor prognostic group in hormonal receptors negative patients (log-rank test, $P=0.027)$. Thus, in this HR negative cohort $(n=20)$ the two early breast cancer patients with SBEM mRNA in BM suffered metastatic progression and died of disease (Fig. 2c).
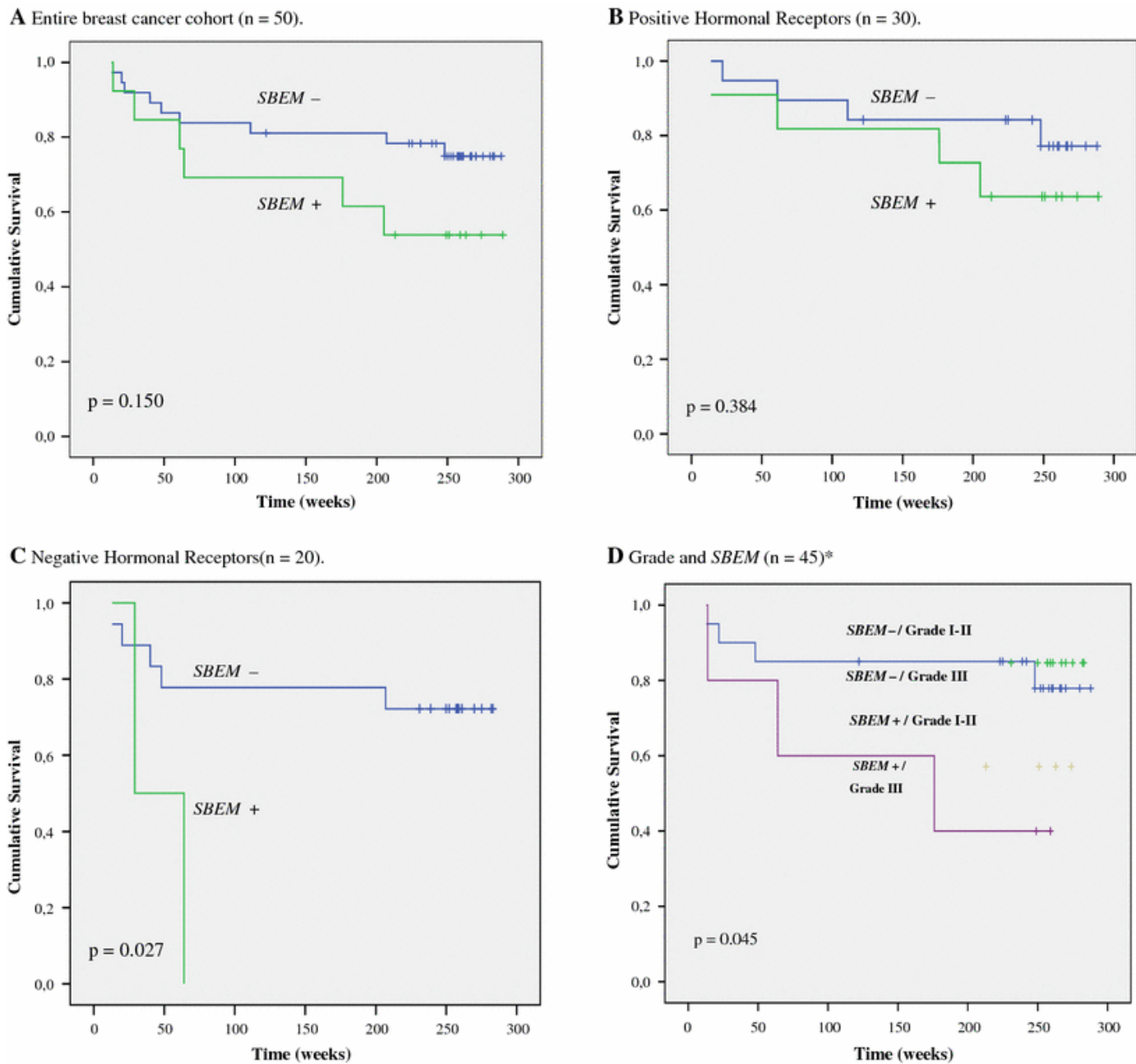

Fig. 2. Kaplan-Meier graphs for time to breast cancer progression according to SBEM mRNA status in bone marrow. Kaplan-Meier estimates are shown for the entire breast cancer cohort (a), positive (b) and negative (c) hormonal receptors and adjusted for grade (d). Symbols on the graph lines represent censored data; $P$-values are given for log rank tests. Asterisk indicates grade was unknown in five patients 
Table 4. Time to breast cancer progression and SBEM bone marrow status determined by RT-PCR: subgroup analysis

\begin{tabular}{|c|c|c|c|c|}
\hline & \multirow{2}{*}{ Bone marrow status } & \multirow{2}{*}{ Patients $(n)$} & \multicolumn{2}{|c|}{ Time to progression (weeks) } \\
\hline & & & Mean & Standard error \\
\hline \multirow{2}{*}{ Grade $1-2$} & SBEM (-) & 20 & 246.1 & 20.7 \\
\hline & SBEM (+) & 7 & 198.7 & 37.9 \\
\hline \multirow{2}{*}{ Grade 3} & $\operatorname{SBEM}(-)$ & 13 & 244.1 & 25.3 \\
\hline & $\operatorname{SBEM}(+)$ & 5 & 154.4 & 44.8 \\
\hline \multirow{2}{*}{ Hormonal receptors (+) } & $\operatorname{SBEM}(-)$ & 19 & 249.9 & 18.9 \\
\hline & $\operatorname{SBEM}(+)$ & 11 & 225.4 & 29.2 \\
\hline \multirow{2}{*}{ Hormonal receptors $(-)$} & $\operatorname{SBEM}(-)$ & 18 & 222.3 & 24.6 \\
\hline & $\operatorname{SBEM}(+)$ & 2 & 46.5 & 17.5 \\
\hline
\end{tabular}

The effect of covariables in TTP was examined using the Cox proportional hazard regression model. Results are showed in Table 5. In multivariate analysis only stage at the time of BM aspirate was statistical significant.

Table 5. Time to breast cancer progression in relation to clinicopathological characteristics and $S B E M$ bone marrow status determined by RT-PCR: Cox proportional hazard regression model

\begin{tabular}{llll}
\hline Variable & Subset & Hazard ratio (95\% confidence interval) & $P$ \\
\hline & & & \\
Univariate analysis & & & 0.002 \\
Active disease & No/yes & $5.47(1.86-16.08)$ & 0.002 \\
Ca 15.3 & Normal/high & $4.97(1.79-13.79)$ & 0.0001 \\
Stage & I-II/II-IV & $12.20(3.39-43.81)$ & 0.030 \\
Lymph Nodes & Negative/positive & $5.22(1.17-23.16)$ & 0.160 \\
SBEM & Negative/positive & $2.10(0.75-5.91)$ & 0.9 \\
Grade & I-II/III & $1.076(0.341-3.393)$ & 0.467 \\
Hormonal receptors & Negative/positive & $0.686(0.249-1.893)$ & 0.098 \\
Multivariate analysis & & & 0.074 \\
Active disease & No/yes & $0.26(0.051-1.287)$ & 0.001 \\
Ca 15.3 & Normal/high & $3.07(0.89-10.51)$ & 0.195 \\
Stage & I-II/III-IV & $16.73(2.99-93.62)$ & 0.239 \\
Lymph nodes & Negative/positive & $2.88(0.58-14.22)$ & \\
SBEM & Negative/positive & $2.17(0.59-7.822)$ & \\
& & & \\
\hline
\end{tabular}




\section{Discussion}

Isolated tumour cell detection in BM by means of immunocytochemical staining has been shown to be an independent prognostic factor in early breast cancer (Pantel and Alix-Panabieres 2007; Braun et al. 2005; Wiedswang et al. 2003). ICC has been considered the gold standard for ITC detection and objective criteria for the evaluation of stained cells has been developed (Borgen et al. 1999). Reverse transcription (RT)-PCR has been used to indirectly detect tumour cells through the expression of epithelial or breast cancer-associated mRNA transcripts in BM, blood and other compartments. Although RT-PCR has been considered more sensitive than antibodybased techniques very few studies have compared the detection rates and diagnostic accuracy of both methodologies (Schoenfeld et al. 1997; Lambrechts et al. 1999; Slade et al. 1999; Ring et al. 2005; Benoy et al. 2004) in BM aspirate. Moreover, different markers have been evaluated in ITC by RT-PCR in breast cancer, and conflicting results about sensitivity and specificity have been reported (reviewed in Lacroix 2006).

In our study we have evaluated for the first time the diagnostic accuracy of SBEM as a potential marker for BM micrometastasis in breast cancer. RT-PCR assay for detection of SBEM mRNA was compared with ICC with $A E 1 / A E 3$ antibody in paired samples obtained from the BM of breast cancer patients. SBEM-specific transcript was found in $26 \%$ of patients, and the detection rate was similar to the percentage of patients with ITC detected, using ICC (24\%). However, concordant results for both tests were found in $66 \%$. Our results are comparable to those previously reported. Slade et al. (1999) reported a concordance of only 50\% between ICC (based in CK staining) and quantitative RT-PCR for CK-19 mRNA when analysing BM samples of primary breast cancer patients. Benoy et al. (2004) compared the detection rates of ICC based in CK staining with RT-PCR in BM in a subgroup of 20 metastatic breast cancer patients. Concordances of 75 and $70 \%$ for CK-19 and $h M A M$ were found respectively.

It has been suggested (Schoenfeld et al. 1997) that some of CK positive cells were not viable or that they were dormant with low metabolic activity as defined by their inability to synthesise mRNA. In fact a single marker to detect and quantify ITC in BM or other samples might lead both to false-negative and false-positive analyses. Moreover and due to the low number of ITC usually present in BM and sensitivity of both methods of detection a stochastic effect and sampling errors cannot be ruled out (Slade et al. 1999).

A previous work (Woelfle et al. 2003) had shown that BM micrometastases are associated to a specific transcriptional signature. Lower expression (at mRNA and protein level) of luminal CKs (CK8, CK18 and CK19) has been found in primary breast tumours with BM micrometastasis. It could be argued that a fraction of disseminated tumour cells in these patients might show a negative CK phenotype and missed in ICC detection. In addition, recent studies have clearly demonstrated that isolated and micrometastatic tumour cells included a remarkably heterogeneous population (Klein et al. 2002; Gangnus et al. 2004; Watson et al. 2007). Loss of luminal CKs and over expression of vimentin suggest that ITC have acquired an epithelial to mesenchymal transition phenotype (Willipinski-Stapelfeldt et al. 2005). We hypothesized that SBEM RT-PCR assay could detect a different population of disseminated tumour cells in BM than those detected in a CK-based assay.

Variability in SBEM mRNA expression levels was identified among different human breast cancer cell lines tested in our previous study (Ayerbes et al. 2008). In mammary tissues, including breast cancer, $S B E M$ expression has been shown to be restricted to luminal epithelial cells (Allinen et al. 2004). Although $S B E M$ expression has been found in the ER-positive, well-differentiated, "luminal epithelial-like" breast cancer cell lines (Lacroix and Leclercq 2004), other studies have shown SBEM gene expression, as assessed by RT-PCR, in more than $90 \%$ of primary or metastatic breast cancers (Miksicek et al. 2002; Colpitts et al. 2002; Brown et al. 2006). In a small subset of primary breast tumours Skliris et al. (2008) have recently shown that SBEM mRNA was detected by RT-PCR in all cases. Furthermore, there was a significant correlation between $S B E M$ protein expression (determined by immunohistochemistry) and $S B E M$ gene expression (determined by RT-PCR and by Northern blot analysis). 
In our study, the detection of $S B E M$ transcript in the BM of patients with breast cancer was significantly correlated with known clinicopathological prognostic factors. SBEM mRNA in BM aspirates were significantly associated with the presence of clinically active disease (47\%, $P=0.021)$ and tumours with positive hormonal receptors $(36.7 \%, P=0.035)$. In addition, association with Her2/neu over-expression $(44.4 \%, P=0.051)$ was close to significance level. A previous report has shown significant association between Her2/neu determined by IHC and increasing amounts of SBEM mRNA (Lacroix and Leclercq 2004) in breast tumours. Using an in silico approach (Ayerbes et al. 2008) we have analysed the expression of SBEM tags in a series of human breast carcinomas SAGE libraries $(n=27)$. SBEM expression were quantified and correlated with the tag numbers of different molecular markers associated with breast cancer progression. Expression of $S B E M$ was significantly correlated (Spearman's rho) to Her2/neu expression $(0.662 ; P=0.000)$.

Although it could appear paradoxical, in our study we found an association of SBEM mRNA in $\mathrm{BM}$ and low proliferating tumours, that was of borderline significance $(36 \%, P=0.067)$. Other authors have found no correlation between the presence of CK-positive cells in BM and Ki67 staining in primary breast tumours (Schindlbeck et al. 2005). However, in a recent study that analysed SBEM protein expression in a large cohort $(n=300)$ of invasive breast cancers, negative association with Ki67 staining was found (Brown et al. 2006). Interestingly, most circulating and micrometastatic tumour cells do not express the proliferation antigen Ki67 and may therefore remain in the state of dormant cell-cycle arrest (Pantel et al. 1993; Muller et al. 2005).

In our study, high tumour grade was significantly associated with ICC detection of ITC in BM as previously described (Braun et al. 2000, 2005). No correlations with other clinical or pathologic characteristic were found. Lack of association of BM status and other prognostic indicators could be dependent of different factors including stage of disease, study design and other methodological aspects. In stages I-III patients, the presence of CK positive cells in BM has been correlated with established prognostic factors, including pT and pN status (Braun et al. 2005; Wiedswang et al. 2003) and hormonal receptor (Braun et al. 2005). However, Braun et al. (2000) found that the incidence of BM micrometastases was similar in patients with lymph-node metastasis and those without it and failed to detect an association between hormonal receptor status and positive CK staining in BM. In addition, in a recently published paper Bidard et al. (2008a) found that ITC detection in BM, using $\mathrm{CK}$ antibodies and specific morphologic features, did not correlate with any of the patient's clinical or pathologic characteristics. Furthermore, in patients with locoregional and distant recurrent breast cancer, the presence of $\mathrm{CK}$ positive cells in $\mathrm{BM}$ at the time of relapse was not correlated with any of the clinical characteristics at the time of primary diagnosis (Janni et al. 2000).

In order to explore the clinical significance of the detection of SBEM mRNA in BM in our series of breast cancer patients, we correlated the RT-PCR results and breast cancer progression. Breast cancer progression was found in six patients (40\%) with SBEM mRNA in BM but only in two patients $(13.3 \%)$ with CK positive cells in BM. Diagnostic accuracy for SBEM RT-PCR for breast cancer progression was estimated in 68\% (95\% CI 53.2-80\%). In addition, Kaplan-Meier survival analysis (Fig. 2) suggests a reduced time for breast cancer progression (TTP) among the $S B E M$ mRNA BM positive patients, although this was not significant (log-rank test, $P=0.150$ ).

Prognostic impact for ITC in BM in breast cancer has shown to be dependent of several factors, including stage of disease, detection method (Bidard et al. 2008b) and molecular subtypes of breast cancer (Naume et al. 2007). Clearly, to ascertain a clinical utility, if any, for SBEM mRNA as a marker for ITC detection, a large study with homogeneous patient cohort and adequate sampled size is needed.

However when we analysed TTP stratifying according to different prognostic factors, presence of $S B E M$ in BM defines poor-prognosis groups adjusting for grade or hormone receptor status (Fig. 2). Tumour grade has been a highly valuable prognostic factor for breast cancer, as highgrade lesions are associated with significantly poorer clinical outcome (Soerjomataram et al. 2008). In addition, distinct transcriptional signatures had been found to be associated with different tumour grades (Ma et al. 2003). Patients with HR-negative breast cancer experienced relapse and progression more often than those with HR-positive tumours during the first 5 years. 
This is not surprising, taking into account the differences in genetic profiles between HR-negative and HR-positive tumours. In line with this, Ignatiadis et al. (2007) have recently analysed the prognostic significance of cytokeratin 19 mRNA detection in blood in early breast cancer patients according to the molecular subtype. They found that $C K-19$ mRNA in blood was an independent prognostic factor for disease-free survival and overall survival only in patients with ER-negative tumours.

\section{Conclusions}

Small breast epithelial mucin might represent a suitable marker for molecular detection of ITCs in $\mathrm{BM}$ in breast cancer patients. However, and when we considered the different transcriptional molecular profiles of breast cancer, a multi-marker and quantitative approach could obtain a higher efficacy. Analysis of prognostic value for SBEM mRNA-based assay should take the heterogeneity and different molecular subtypes of breast cancer into account.

\section{Acknowledgments}

This study was supported by grant 2000-5435256011 from Universidade da Coruña. S. Díaz-Prado is supported by an Isidro Parga Pondal research contract by Xunta de Galicia. The authors wish to thank S. Pértega Díaz for excellent statistical assistance. Cancer research in our laboratory is supported by the "Fundación Juan Canalejo-Marítimo de Oza."

\section{Conflict of interest statement}

None declared.

\section{References}

AceView: a comprehensive cDNA-supported gene and transcripts annotation. http://www.ncbi.nlm.nih.gov/IEB/Research/Acembly/av.cgi?exdb=AceView\&db=36a\&term= SBEM\&submit=Go

Allinen M, Beroukhim R, Cai L et al (2004) Molecular characterization of the tumour microenvironment in breast cancer. Cancer Cell 6:17-32. doi: 10.1016/j.ccr.2004.06.010

Ayerbes MV, Díaz-Prado S, Ayude D et al (2008) In silico and in vitro analysis of small breast epithelial mucin as a marker for bone marrow micrometastasis in breast cancer. Adv Exp Med Biol 617:331-339. doi: 10.1007/978-0-387-69080-3_31

Benoy IH, Elst H, Van der Auwera I et al (2004) Real-time RT-PCR correlates with immunocytochemistry for the detection of disseminated epithelial cells in bone marrow aspirates of patients with breast cancer. Br J Cancer 91:1813-1820. doi: $10.1038 /$ sj.bjc. 6602189

Bidard FC, Vincent-Salomon A, Gomme S et al (2008a) Disseminated tumor cells of breast cancer patients: a strong prognostic factor for distant and local relapse. Clin Cancer Res 14:3306-3311. doi: 10.1158/1078-0432.CCR-07-4749

Bidard FC, Vincent-Salomon A, Sigal-Zafrani B et al (2008b) Prognosis of women with stage IV breast cancer depends on detection of circulating tumor cells rather than disseminated tumor cells. Ann Oncol 19:496-500. doi: 10.1093/annonc/mdm507

Borgen E, Naume B, Nesland et al (1999) Standardisation of the immunocytochemical detection of cancer cells inbone marrow and blood. I. Establishment of objective criteria for the evaluation of immunostained cells. Cytotherapy 1:377-388. doi: 10.1080/0032472031000141283

Braun S, Naume B (2005) Circulating and disseminated tumour cells. Review Article. J Clin Oncol 23:1623-1626. doi: 10.1200/JCO.2005.10.073

Braun S, Pantel K, Müller P et al (2000) Cytokeratin-positive cells in the bone marrow and survival of patients with stage I, II or III breast cancer. N Engl J Med 342:525-533. doi: 10.1056/NEJM200002243420801

Braun S, Vogl F, Naume B et al (2005) A pooled analysis of bone marrow micrometastasis in breast cancer. N Engl J Med 353:793-802. doi: 10.1056/NEJMoa050434 
Brown NM, Stenzel TT, Friedman PN, Henslee J, Huper G, Marks JR (2006) Evaluation of expression based markers for the detection of breast cancer cells. Breast Cancer Res Treat 97:41-47. doi: 10.1007/s10549-005-9085-8

Choesmel V, Pierga JY, Nos C, Vincent-Salomon A, Sigal-Zafrani B, Thiery JP, Blin N (2004) Enrichment methods to detect bone marrow micrometastases in breast carcinoma patients: clinical relevance. Breast Cancer Res 6:R556-R569. doi: 10.1186/bcr898

Colpitts TL, Billing P, Granados E et al (2002) Identification and immunohistochemical characterization of a mucin-like glycoprotein expressed in early stage breast carcinoma. Tumour Biol 23:263-278. doi: 10.1159/000068566

Ferlay J, Autier P, Boniol M, Heanue M, Colombet M, Boyle P (2007) Estimates of the cancer incidence and mortality in Europe in 2006. Ann Oncol 18:581-592. doi: 10.1093/annonc/mdl498

Gangnus R, Langer S, Breit E, Pantel K, Speicher MR (2004) Genomic profiling of viable and proliferative micrometastatic cells from early-stage breast cancer patients. Clin Cancer Res 10:3457-3464. doi: 10.1158/1078-0432.CCR-03-0818

Houghton RL, Dillon DC, Molesh DA et al (2001) Transcriptional complementarity in breast cancer: application to detection of circulating tumour cells. Mol Diagn 6:79-91. doi: 10.2165/00066982-200106020-00003

Ignatiadis M, Xenidis N, Perraki M et al (2007) Different prognostic value of cytokeratin-19 mRNA positive circulating tumour cells according to estrogen receptor and HER2 status in early-stage breast cancer. J Clin Oncol 25:5194-5202. doi: 10.1200/JCO.2007.11.7762

Janni W, Gastroph S, Hepp F et al (2000) Prognostic significance of an increased number of micrometastatic tumor cells in the bone marrow of patients with first recurrence of breast carcinoma. Cancer 88:2252-2259. doi: 10.1002/(SICI)10970142(20000515)88:10<2252::AID-CNCR8>3.0.CO;2-Q

Klein CA, Blankenstein TJF, Schmidt-Kittler O et al (2002) Genetic heterogeneity of single disseminated tumour cells in minimal residual cancer. Lancet 360:683-689. doi: 10.1016/S0140-6736(02)09838-0

Kruger WH, Jung R, Detlefsen B et al (2001) Interference of cytokeratin-20 and mammaglobinreverse-transcriptase polymerase chain assays designed for the detection of disseminated cancer cells. Med Oncol 18:33-38. doi: 10.1385/MO:18:1:33

Lacroix M (2006) Significance, detection and markers of disseminated breast cancer cells. Endocr Relat Cancer 13:1033-1067. doi: 10.1677/ERC-06-0001

Lacroix M, Leclercq G (2004) Relevance of breast cancer cell lines as models for breast tumours: an update. Breast Cancer Res Treat 83:249-289. doi: 10.1023/B:BREA.0000014042.54925.cc

Lambrechts AC, Bosma AJ, Klaver SG, Top B, Perebolte L, van't Veer LJ, Rodenhuis S (1999) Comparison of immunocytochemistry, reverse transcriptase polymerase chain reaction, and nucleic acid sequence-based amplification for the detection of circulating breast cancer cells. Breast Cancer Res Treat 56:219-231. doi: 10.1023/A:1006261731125 PubMedCrossRefGoogle Scholar

Ma X-J, Salunga R, Tuggle JT et al (2003) Gene expression profiles of human breast cancer progression. Proc Natl Acad Sci USA 100:5974-5979. doi: 10.1073/pnas.0931261100

Miksicek RJ, Myal Y, Watson PH, Walker C, Murphy LC, Leygue E (2002) Identification of a novel breast- and salivary gland-specific, mucin-like gene strongly expressed in normal and tumour human mammary epithelium. Cancer Res 62:2736-2740

Muller V, Stahmann N, Riethdorf S et al (2005) Circulating tumour cells in breast cancer: correlation to bone marrow micrometastases, heterogeneous response to systemic therapy and low proliferative activity. Clin Cancer Res 11:3678-3685. doi: 10.1158/1078-0432.CCR-042469

Naume B, Zhao X, Synnestvedt M et al (2007) Presence of bone marrow micrometastasis is associated with different recurrence risk within molecular subtypes of breast cancer. Mol Oncol 1:160-171. doi: 10.1016/j.molonc.2007.03.004

Pantel K, Alix-Panabieres C (2007) The clinical significance of circulating tumour cells. Nat Clin Pract Oncol 4:62-63. doi: 10.1038/ncponc0737

Pantel K, Schlimok G, Braun S et al (1993) Differential expression of proliferation-associated molecules in individual micrometastatic carcinoma cells. J Natl Cancer Inst 85:1419-1424. doi: 10.1093/jnci/85.17.1419

Pantel K, Schlimok G, Angstwurm M et al (1994) Methodological analysis of immunocytochemical screening for disseminated epithelial tumour cells in bone marrow. J Hematother 3:165-173

Ring AE, Zabaglo L, Ormerod MG, Smith IE, Dowsett M (2005) Detection of circulating epithelial cells in the blood of patients with breast cancer: comparison of three techniques. $\mathrm{Br}$ J Cancer 92:906-912. doi: 10.1038/sj.bjc.6602418 
Rozen S, Skaletsky HJ (2000) Primer3 on the WWW for general users and for biologist programmers. In: Krawetz S, Misener S (eds) Bioinformatics methods and protocols: methods in molecular biology. Humana Press, Totowa, pp 365-386

Schindlbeck C, Kampik T, Janni W et al (2005) Prognostic relevance of disseminated tumour cells in the bone marrow and biological factors of 265 primary breast carcinomas. Breast Cancer Res 7:R1174-R1185. doi: 10.1186/bcr1360

Schoenfeld A, Kruger KH, Gomm J et al (1997) The detection of micrometastases in the peripheral blood and bone marrow of patients with breast cancer using immunohistochemistry and reverse transcriptase polymerase chain reaction for keratin 19. Eur J Cancer 33:854-861. doi: 10.1016/S0959-8049(97)00014-2

Skliris GP, Hube' F, Gheorghiu I et al (2008) Expression of small breast epithelial mucin (SBEM) protein in tissue microarrays (TMAs) of primary invasive breast cancers. Histopathology 52:355-369. doi: 10.1111/j.1365-2559.2007.02955.x

Slade MJ, Smith BM, Sinnett HD, Cross NC, Coombes RC (1999) Quantitative polymerase chain reaction for the detection of micrometastases in patients with breast cancer. J Clin Oncol $17: 870-879$

Soerjomataram I, Louwman MW, Ribot JG, Roukema JA, Coebergh JWW (2008) An overview of prognostic factors for long-term survivors of breast cancer. Breast Cancer Res Treat 107:309-330. doi: 10.1007/s10549-007-9556-1

Verdecchia A, Francisci S, Brenner H et al (2007) Recent cancer survival in Europe: a 2000-02 period analysis of EUROCARE-4 data. Lancet Oncol 8:784-796. doi: 10.1016/S14702045(07)70246-2

Watson MA, Ylagan LA, Trinkaus KM et al (2007) Isolation and molecular profiling of bone marrow micrometastases identifies TWIST1 as a marker of early tumour relapse in breast cancer patients. Clin Cancer Res 13:5001-5009. doi: 10.1158/1078-0432.CCR-07-0024

Wiedswang G, Borgen E, Karesen R et al (2003) Detection of isolated tumour cells in bone marrow is an independent prognostic factor in breast cancer. J Clin Oncol 21:3469-3478. doi: 10.1200/JCO.2003.02.009

Willipinski-Stapelfeldt B, Riethdorf S, Assmann V et al (2005) Changes in cytoskeletal protein composition indicative of an epithelial-mesenchymal transition in human micrometastatic and primary breast carcinoma cells. Clin Cancer Res 11:8006-8014. doi: 10.1158/10780432.CCR-05-0632

Woelfle U, Cloos J, Sauter G et al (2003) Molecular signature associated with bone marrow micrometastasis in human breast cancer. Cancer Res 63:5679-5684 